\title{
O DUALISMO DO ENSINO BRASILEIRO NO ENSINO MÉDIO INIEGRADO
}

THE DUALISM OF BRAZILIAN TEACHING IN INTEGRATED SECONDARY SCHOOL EDUCATION

EL DUALISMO DE LA ENSEÑANZA BRASILEÑA EN LA ENSEÑANZA MEDIO INTEGRADO

\author{
Joceli Pereira Roberto \\ Instituto Federal de Educação, Ciência e Tecnologia do Triângulo Mineiro. \\ E-mail: joceliproberto@gmail.com \\ Welisson Marques \\ Instituto Federal de Educação, Ciência e Tecnologia do Triângulo Mineiro. \\ E-mail: welissonmarques@iftm.edu.br
}

\begin{abstract}
RESUMO
Acreditando na educação como ferramenta emancipadora dos indivíduos é que o presente trabalho propõe a discussão e reflexão sobre a formação histórica da sociedade brasileira e como isso refletiu em sua estrutura educacional, tenciona como contribuição para a diminuição da distância entre o discurso e a prática docente, com vias a minimizar a dicotomia do ensino brasileiro. A dicotomia refere-se à dualidade existente entre um ensino propedêutico e o ensino técnico. O dualismo é alusivo a um ensino que valoriza determinadas disciplinas e a um público elitizado, com o objetivo de alçá-los a um nível superior, e de outro lado, um ensino que objetiva capacitar mão de obra para o mercado de trabalho. Será feita uma retrospectiva do contexto sócio-histórico da formação da sociedade brasileira, cuja construção está entrelaçada à educação, com o intuito de demonstrar como as características de nossa sociedade refletem diretamente na educação e no ensino brasileiro.
\end{abstract}

PALAVRAS-CHAVE: Ensino. Dualidade. Ensino Médio Integrado.

\begin{abstract}
Believing in education as an emancipating tool of individuals is that the present work proposes the discussion and reflection on the historical formation of Brazilian society and how this reflected in its educational structure, intends as contribution to the reduction of the distance between the discourse and the teaching practice, with ways to minimize the dichotomy of Brazilian education. The dichotomy refers to the duality between propaedeutic and technical education. The dualism is alluding to a teaching that values certain disciplines and an elite public, with the goal of raising them to a higher level, and on the other, a teaching that aims to qualify labor for the labor market. A retrospective of the socio-historical context of the formation of Brazilian society will be made, whose construction is intertwined with education, in order to demonstrate how the characteristics of our society reflect directly on Brazilian education and education.
\end{abstract}

KEYWORDS: Teaching. Duality. Integrated Secondary School Education.

\section{RESUMEN}

Creciendo en la educación como herramienta emancipadora de los individuos es que el presente trabajo propone la discusión y reflexión sobre la formación histórica de la sociedad brasileña y como eso reflejó en su estructura educativa, tiene como contribución a la disminución de la distancia entre el discurso y la práctica docente, con el fin de minimizar la dicotomía de la enseñanza brasileña. La dicotomía se refiere a la dualidad existente entre una enseñanza propedéutica y la enseñanza técnica. El dualismo es alusivo a una enseñanza que valora determinadas disciplinas ya un público elitizado, con el objetivo de alzarlos a un nivel superior, y por otro lado, una enseñanza que objetiva capacitar mano de obra para el mercado de trabajo. Se hará una retrospectiva del contexto socio-histórico de la formación de la sociedad brasileña, cuya construcción está entrelazada a la 


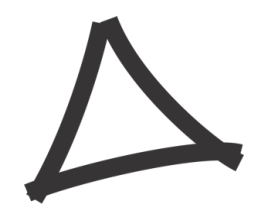

educación, con el propósito de demostrar cómo las características de nuestra sociedad reflejan directamente en la educación y en la enseñanza brasileña.

PALABRAS-CLAVE: Educación. Dualidad. Enseñanza Media Integrada.

\section{INTRODUÇÃO}

É sabido que a dualidade do ensino brasileiro é histórica e porque não dizer ainda contemporânea. Verificamos que, durante séculos, o ensino em nosso país foi dividido entre ensino dos ricos e ensino dos pobres (MOURA, 2007; CIAVATTA, 2005). Durante muito tempo a educação foi voltada apenas para as elites, que possuíam condições de enviar seus filhos para escolas de qualidade e universidades. Uma educação propedêutica dirigida àqueles que poderiam adentrar em um ensino superior.

Nesse contexto, entre as camadas pobres da população e junto aos marginalizados havia uma política de assistencialismo em que o ensino profissionalizante era oportunizado a fim de proporcionar a esses a admissão ao mercado de trabalho. Ainda, observamos resquícios desse tipo de pensamento, que parece permanecerem alicerçados em nossa sociedade. Isso é perceptível na elaboração de leis, que possibilitaram uma reformulação da educação básica e do ensino superior, mas que distinguia notoriamente a educação profissional, quanto a sua finalidade ${ }^{1}$.

A Lei 9.394/96 (Lei de Diretrizes e Bases) em seu Art. 35, inciso III, coloca como uma das finalidades do ensino médio, o aprimoramento do educando como pessoa humana, incluindo a formação ética e o desenvolvimento da autonomia intelectual e do pensamento crítico. Contudo, essa mesma finalidade não é encontrada nos poucos artigos que regem o ensino profissional. No Capítulo III, da Lei 9.394/96, referente à educação profissional, em seu Art. 39 indica que a educação profissional conduz ao permanente desenvolvimento de aptidões para a vida produtiva. Observa-se que o propósito deste ensino seria potencializar os dons para a produção e não para autonomia intelectual.

Nessa perspectiva, o que se percebe é a dualidade entre um ensino academicista, praticado pelas escolas privadas, que objetivam a aprovação no vestibular e de outro lado, uma

${ }^{1}$ É tendenciosa a finalidade destinada ao ensino profissional que não visa à formação integrada, mas torna fragmentado o ensino objetivando as necessidades do mercado. O foco é econômico e não educacional.

\begin{tabular}{l|l|l|l|l|l|l|} 
(C) Rev. Triang. & Uberaba, MG & v.11 & n.1 & p. 20-32 & Jan./Abr. 2018 & ISSN 2175-1609
\end{tabular} 


\section{$\Delta$}

educação técnica que prepara uma mão de obra para o mercado de trabalho. A fim de superar essa dualidade acredita-se em um ensino médio que venha a garantir a integralidade de uma educação básica, com conteúdo científico essencial para um pleno desenvolvimento do homem e que também contemple a formação profissional, integrando ambas e proporcionando ao estudante uma formação completa.

Nesse sentido, este trabalho almeja analisar se a visão omnilateral é realizada no ensino médio integrado do Instituto Federal do Triângulo Mineiro, especificamente por parte de docentes que lecionam a disciplina Geografia. O termo omnilateral está associado à educação socialista $^{2}$, conforme o pensamento Marxista, que se opunha a uma educação unilateral, que formasse somente sujeitos para o mercado de trabalho. A educação omnilateral seria aquela na qual o homem se sentiria completo, pois conceberia o homem no todo (físico, mental, cultural, social, afetivo, político etc.). Seria uma educação que superaria a divisão trabalho manual e trabalho intelectual.

Partindo do princípio de que a Geografia é uma ciência que se preocupa com as relações estabelecidas entre a sociedade e o meio, tendo por base o conhecimento e análise do espaço, ela também busca decifrar as relações de poder concretizadas na espacialidade. Desse modo, torna-se pertinente que se levante as seguintes indagações: o discurso do sujeito-professor de Geografia está inteirado com as demais disciplinas técnicas do ensino médio integrado? Por meio de quais concepções de integração? Essas concepções são identificáveis no discurso do sujeito-professor de Geografia?

A princípio, parece-nos que muitos professores não possuem uma visão integradora, no sentido de que a educação geral seja inerente à educação profissional. Possuem uma visão dualista em que o ensino não é articulado com as disciplinas técnicas, decorrente da falta de conhecimento a respeito de integração. Sendo assim, por meio das análises discursivas se buscará identificar as concepções de integração que transpassam os discursos do sujeitoprofessor de Geografia.

Nessa esteira, refletiremos sobre os sujeitos historicamente construídos e a posição assumida pelo sujeito que é decorrente de seu discurso, sob o fulcro da Análise do Discurso -

\footnotetext{
${ }^{2}$ É importante ressaltar que o presente trabalho não preconiza que o ensino deva ser socialista, mas apenas sinalizando que um dos intuitos dessa educação era considerar o homem no seu todo, fator primordial para que o ensino seja integral e não fragmentado. 


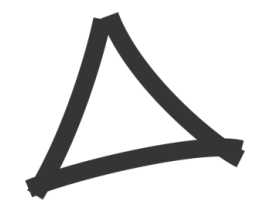

(AD), linha francesa, ao se tomar os sentidos produzidos nesses discursos. Assim o objetivo do presente artigo é verificar as "convicções" e a posição que assume o sujeito-professor de Geografia, de acordo com o que é recorrente em seu discurso.

Torna-se fundamental, que o professor de Geografia do ensino integrado tenha compreensão a respeito do que é uma formação integrada e o comprometimento de torná-la possível. Sabemos que as dificuldades fazem parte de qualquer trajetória educacional, mas a identificação dos obstáculos, em especial no ensino médio integrado, permitirá uma ação mais eficaz do professor possibilitando uma maior integralização do ensino. Acreditamos que o grau de entendimento do mundo depende de como os indivíduos buscam o conhecimento. Nesse sentido, a educação tem o compromisso de formar cidadãos para o alcance desse conhecimento.

A consciência social será desenvolvida no aprimoramento da aprendizagem, que contribui para a formação pessoal modificando a visão de mundo e dilatando a capacidade de análise. Essa prática poderá corroborar com as discussões acerca dessa problemática minimizando a dicotomia do ensino brasileiro e colaborando para um ensino menos dual e mais integralizado, a fim de eliminar os pré-conceitos a respeito do ensino técnico.

Diante disso, torna-se necessária uma retrospectiva do contexto sócio-histórico da formação da sociedade brasileira cuja construção está entrelaçada à educação, com o intuito de demonstrar como as características de nossa sociedade refletem diretamente na educação e na prática do ensino brasileiro. Além de evidenciar a dualidade existente no ensino e a dicotomia entre o ensino médio e o ensino técnico.

\section{REFERENCIAL TEÓRICO}

Para entender a educação dualista, na qual se caracteriza o nosso país, e os resquícios de desconfiança, que rondam o ensino profissional, é necessário compreender o contexto histórico educacional brasileiro. A sociedade brasileira foi construída em uma base de enormes contradições. Podemos aqui ressaltar a dominação, o extermínio, a exploração, a escravidão que geraram enormes desigualdades tanto econômicas como sociais. Não nos foi possível, em uma sociedade explorada e sucessivamente exploradora, uma formação de condições que permitisse uma participação popular. 


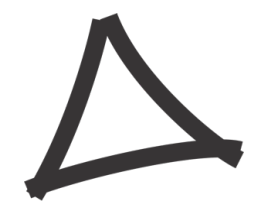

As grandes extensões de terras, no Brasil, favoreciam o crescimento dos latifúndios, o que também contribuía para o aumento da desigualdade e da escravidão. Como aponta Carvalho (2004, p. 19), "o fator mais negativo para a cidadania foi a escravidão." E, em nosso país, ela durou cerca de trezentos anos, permeou todos os ciclos econômicos brasileiros até o início do ciclo do café. A escravidão estava arraigada na sociedade brasileira. Em uma estrutura escravocrata tão rígida que penetrava todos os grupos, órgãos e categorias, não havia espaço suficiente para experiências democráticas.

Desta feita, reconhece Carvalho (2004, p. 21), "entre escravos e senhores, existia uma população legalmente livre, mas a que faltavam quase todas as condições para o exercício dos direitos civis, sobretudo a educação". A maior parte da população brasileira era analfabeta. Não era necessário preocupar-se com educação ${ }^{3}$, se o objetivo era exploração. Não houve essa responsabilidade em educar a população, na ocupação do território, durante o povoamento e nem mesmo após a independência.

Nesse sentido, Freire (1983, p. 71) assevera que "não há povo", quando se refere à sociedade brasileira. Bem como Carvalho (2004, p. 23), que "não havia república no Brasil, não havia sociedade política, isto é, não havia cidadãos". Mesmo após 1822, os direitos políticos foram evidenciados em detrimento dos direitos civis. A escravidão não foi atingida e permaneceu. Em relação à educação, manteve-se o tratamento de descrédito. Afinal, quem tinha condições poderia estudar na Europa. E os que não tinham condições dedicavam-se ao trabalho e isso era suficiente. A abolição dos escravos ocorreu em 1888, um ano antes da Proclamação da República, o que colocou o Brasil como o último país a libertar seus escravos.

A maioria dos escravos analfabetos não tinha para onde ir, não possuía terras e, no final, muitos continuaram na mesma situação, com a única diferença de que pela lei eram libertos. $\mathrm{O}$ fato de o Brasil ter tido um período tão prolongado de escravidão, além de outros problemas como o analfabetismo, contribuiu para formar uma população excluída, renegada e sujeita a trabalhos não valorados. Cooperou para que o Brasil estivesse a passos distantes de outros países, nos quais os negros já frequentavam universidades.

\footnotetext{
${ }^{3}$ Baseado na concepção de Freire de uma educação para responsabilidade social e política, que possibilite ao homem uma discussão crítica sobre a sua problemática. Considera-se também que essa não preocupação se dá por "boa parte" (não significa totalidade) da Elite de então.
} 


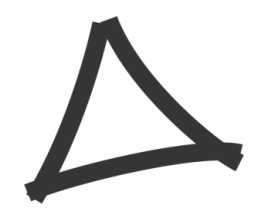

Somente quando analisamos nosso passado histórico é que compreendemos várias realidades presentes na sociedade brasileira. Em nosso contexto, observamos que, enquanto em outros países havia uma evolução, como exemplo, nos países europeus que ampliavam a sua vivência política, no sentido de direitos políticos e civis, no Brasil havia um retrocesso com experiências que ora eram traumáticas ora restritas.

Segundo os dados do Ministério da Educação (2009, p. 2), em 1889, o número total de fábricas instaladas era de 636 estabelecimentos, com um total de 54 mil trabalhadores, com uma população total de 14 milhões de habitantes. Já em 1906, no Rio de Janeiro, Nilo Peçanha inicia o ensino técnico. Entretanto, havia desde a fundação do ensino técnico a sua associação à classe trabalhadora que, diga-se de passagem, era fundamentalmente formada pelos exescravos, os excluídos e os analfabetos. De acordo com Carvalho (2004, p. 65), "os dados do censo de 1920, indicavam que no Brasil havia 30 milhões de habitantes, em que apenas 24\% sabiam ler e escrever".

Naturalmente, foi associada a destinação do ensino técnico unicamente às camadas mais baixas da população. Isso acarretou o preconceito para com o ensino profissional, que se percebe até os dias atuais. Há de se pensar que com as modificações ocorridas na sociedade, já existia uma nítida distinção entre o ensino para formação de dirigentes, do destinado aos trabalhadores. No Brasil, como afirma Ciavatta (2005, p. 87), “o dualismo das classes sociais, do acesso aos bens e aos serviços produzidos pelo conjunto da sociedade, se enraíza no tecido social através de séculos de escravismo e de discriminação do trabalho manual”. Desde então, a dualidade se fez presente nos alicerces da educação brasileira.

Constata-se que o panorama político e econômico do país exigia uma classe de trabalhadores preparada para suprir as necessidades da indústria bem como contribuir para a manutenção do governo vigente. Visto que a educação profissional estava a serviço de interesses políticos e econômicos, não era entendida como uma garantia aos direitos sociais, conforme pontuam os autores:

A metodologia de ensino correspondia a um enquadramento intelectual que condicionava o aprendiz a limitar-se à reprodução dos conhecimentos já elaborados, além do que conduzia a uma acomodação ao status de operário e de conformismo à ordem social. Cabia à instituição de ensino profissional o papel de reproduzir política e ideologicamente as condições de trabalho da fábrica, indispensáveis à produção, 


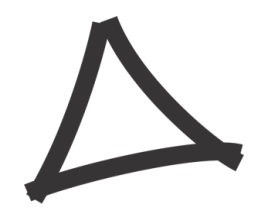

onde alguém tinha o direito de mandar e o poder de fazer obedecer (ARAÚJO; RODRIGUES, 2010, p. 53).

Verifica-se que não era objetivo da educação profissional desenvolver uma capacidade crítica ou possibilitar a autonomia. $\mathrm{O}$ homem não era visto em sua omnilateralidade ${ }^{4} \mathrm{o}$ que fazia com que sua formação fosse apenas focada no técnico. Nesse sentido, assevera Frigotto (1983, p. 40), "a questão que está em jogo não é a valorização do trabalho e do trabalhador, mas a preservação e a formação de uma força de trabalho adaptada aos interesses da produção".

No entanto, ao mesmo tempo em que o ensino técnico limitava-se ao trabalho, o ensino propedêutico tinha como finalidade a preparação de seus educandos para alçar o ensino superior. Esse dualismo entre o ensino geral e o ensino profissional ficou mais evidente na década de 1940. Nesse sentido, esclarece Ciavatta (2005, p. 87), "o dualismo é evidenciado a partir de 1940 quando a educação nacional foi organizada por leis orgânicas 5 . Separação entre os que devem ter ensino secundário e a formação propedêutica".

A questão crucial do ensino técnico no Brasil é que ele, em um primeiro momento, destinou-se apenas a solucionar os problemas das indústrias. Bastava ensinar a apertar o parafuso, a solucionar situações problemas com a máquina e nada além da própria máquina. Na década de 1980, começa a se desenvolver um novo tipo de pensamento, tenta-se remover a dicotomia existente no ensino e nas questões sociais. Contudo, modificar séculos de dominação e superar a visão de separação entre trabalho braçal e trabalho intelectual não seria do dia para a noite.

Por mais que verificasse políticas com o propósito de diminuir essa dicotomia, o trabalhador ainda era visto como ser inferior, que deveria se sujeitar à "superioridade" do proprietário, enfim, à dominação do capital. Essa cultura de dominação, de se subjugar, perpetuou até os dias atuais. É importante observar que nos países desenvolvidos também ocorriam diferenças sociais, porém a distinção é que essas diferenças foram minimizadas com a conquista dos direitos sociais e, também, com difusão da educação básica para todos. A

\footnotetext{
${ }^{4}$ Refere-se ao pensamento marxista que sustenta a ideia de que o homem deve ser visto na sua integralidade, de forma completa, considerando a sua convivência em sociedade e de seu trabalho.

${ }^{5}$ Um exemplo foram as Leis Orgânicas da Educação Nacional - Reforma Capanema (Decreto $n^{\circ}$ 4.244/ 42; Decreto $^{\circ}$ 4.073/42; Decreto $n^{\circ}$ 6.141/43; Decreto $n^{\circ}$ 8.529/46; Decreto $n^{\circ}$ 8.530/46; Decreto $n^{\circ}$ 9.613/46; Decreto $\left.\mathrm{n}^{\circ} 4.048 / 42\right)$ e a Lei $\mathrm{n}^{\circ} 4.024 / 61$. 


\section{$\Delta$}

educação vista com a finalidade primeira de desenvolver uma autonomia intelectual no educando e não para produzir apenas uma mão de obra, para o mercado de trabalho.

\section{MATERIAIS E MÉTODOS}

A pesquisa qualitativa sobre o Dualismo do Ensino Médio Brasileiro no Ensino Médio Integrado, em um primeiro momento recorreu a uma vasta revisão bibliográfica, pois para o levantamento da discussão sobre o tema proposto, se fez necessário um aporte bibliográfico, por meio de leituras específicas de obras e artigos científicos alusivos à temática. Essas leituras é que deram o suporte e motivação para o estudo e aproveitamento de conceitos e princípios fundantes da análise e interpretação dos processos pesquisados.

O trabalho sobre o Dualismo do Ensino Brasileiro no Ensino Médio Integrado investigará se ainda é presente essa dualidade histórica, entre ensino propedêutico e ensino técnico no Ensino Médio Integrado. Visto que, em um ensino que visa a integração, não é adequado ainda ocorrer uma dicotomia entre as matérias técnicas e básicas. Para essa investigação, a pesquisa se fundamentará na Análise do Discurso francesa, propondo-se a analisar, entre outros aspectos, as concepções de integração que permeiam os discursos do sujeito-professor de Geografia, a partir de suas experiências como docentes.

Quanto à metodologia utilizada, para investigar a presença da dualidade no Ensino Médio Integrado recorreu-se a técnica de entrevistas, em que, algumas perguntas previamente formuladas são respondidas oralmente pelos entrevistados. Assim, optou-se por entrevistar 08 (oito) professores de Geografia, do Instituto Federal de Educação, Ciência e Tecnologia do Triângulo Mineiro - IFTM Campus Uberaba, Campus Uberaba Parque Tecnológico e Campus Uberlândia. As entrevistas aconteceram com prévio agendamento de data e local, as mesmas foram gravadas e, posteriormente, transcritas para a análise dos discursos do sujeito-professor de Geografia. Os resultados da pesquisa serão efetivados com base nos dados coletados nas entrevistas. É oportuno registrar que a pesquisa encontra-se em andamento em suas análises.

Com os dados até o momento coletados e algumas pré-análises já realizadas é possível verificar as concepções de integração que permeiam os discursos do sujeito-professor de Geografia, bem como apontar alguns resultados prévios sobre a dualidade no Ensino Médio Integrado. Desse modo, é oportuno questionar-se se atualmente ainda ocorre uma visão 


\section{$\Delta$}

preconceituosa em relação ao ensino profissional e se a dualidade tão característica da educação brasileira ainda persiste na prática.

\section{ANÁLISE DOS DADOS E RESULTADOS}

Nessa esteira, refletiremos sobre os sujeitos historicamente construídos e a posição assumida pelo sujeito que é decorrente de seu discurso. Assim, o objetivo da presente pesquisa é verificar as "convicções" e a posição que assume o sujeito-professor de Geografia, de acordo com o que é recorrente em seu discurso. Posto isto, por meio das análises discursivas se buscará, ao término da pesquisa, confirmar e identificar as concepções de integração que transpassam os discursos do sujeito-professor de Geografia.

A partir dos dados coletados em entrevistas e de algumas pré-análises realizadas, a princípio, parece-nos que muitos professores não possuem uma visão integradora, no sentido de que a educação geral seja inerente à educação profisssional. Possuem uma visão dualista em que o ensino não é articulado com as disciplinas técnicas, decorrente da falta de conhecimento a respeito de integração. Destacam-se dentre os discursos os seguintes fragmentos que indicam esse entendimento:

Fica muito assim, eu trabalho a minha parte e ele trabalha a dele. Às vezes eu entro na sala [...] é [...] eu sei que o professor que ele já deu aquilo para os alunos: Gente! Vocês já viram isso? Já. Então, vamos ver isso agora pela visão da Geografia, porque é diferente, né, a visão que tem o professor de solos, porque para o professor de solos na agropecuária o plantio, aquela coisa toda, pra gente da Geografia, a gente pensa além dessa questão do plantio, a conservação, o que isso vai impactar para as vidas futuras dentre outras coisas. Tem essa diferença, então eu preciso sentar realmente, mas a gente não consegue (ENTREVISTADO 01).

Pra te falar assim, que essa integração existe que a gente consegue realmente trabalhar de forma integrada, médio e técnico eu não enxergo isso. Eu acho assim, aqui nós temos, até a integração dos professores mesmo, os professores da técnica são mais entre eles mesmos, e os da básica que a gente fala que é o comum eles se integram muito mais, então acaba assim que existe um pouco dessa divisão eu sinto muito isso, entre nós professores e principalmente com relação ao conteúdo pra conseguir colocar isso de forma integrada, eu acho muito difícil (ENTREVISTADO 02).

Também temos as reuniões com os professores por curso, mas a meu ver apesar de existir esse espaço, nós ainda não conseguimos romper aquela distância entre as disciplinas. Faz três anos que foi criada uma disciplina que se chama Projeto Integrador, existe em todos os cursos técnicos, e eu acompanho mais próximo o curso de Meio Ambiente e já coordenei essa disciplina há um ano. E aí, a gente percebe na prática a dificuldade que é, mesmo tendo uma disciplina, um espaço para desenvolver esse trabalho integrado, vem a dificuldade cultural nossa, da nossa própria formação, das nossas limitações, da nossa falta de experiência em trabalhar de forma integrada 


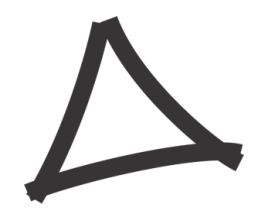

e a gente esbarra naquelas gavetinhas das disciplinas, em que a maior parte dos professores foi formado, tiveram formação dessa forma, e agora tem dificuldade de romper com isso (ENTREVISTADO 04).

No Brasil, a lógica econômica prevaleceu quando se pensou no ensino profissional. Isso fez com que o foco fosse a preparação para o mercado de trabalho e não a promoção do conhecimento, permitindo que o mesmo alcançasse todas as camadas da população de forma igualitária. Diante disso, aos desfavorecidos de condições financeiras destinou-se uma educação assistencialista com políticas que tentam facilitar o acesso à educação, contudo, mascaram uma problemática mais profunda. No caso do ensino técnico, a dualidade histórica, indica que aos pobres foi destinado um conhecimento que apenas preparasse para subsistência. Nesse sentido declara:

Este é o sentido da história da formação profissional no Brasil, uma luta política permanente entre duas alternativas: a implementação do assistencialismo e da aprendizagem operacional versus a proposta da introdução dos fundamentos da técnica e das tecnologias, o preparo intelectual (CIAVATTA, 2005, p. 88).

Pode-se concluir que educação está intimamente ligada à cidadania e às questões sociais. Esse pensamento foi estudado na década de 70 por filósofos e sociólogos europeus que diziam que a origem social influenciaria na trajetória escolar e, desse modo, a escola refletia a divisão das classes sociais. Destacam-se os sociólogos Baudelot e Establet que formularam a teoria da escola dualista. Certo é que a escola reflete as contradições existentes na sociedade e a educação, por sua vez, não é neutra, ela reproduz a política de sua época.

\begin{abstract}
A função real da escola não é em absoluto fazer desabrochar harmonicamente o indivíduo ou desenvolver suas aptidões pessoais; este é um sonho abstrato dos psicólogos. Ao contrário, o papel da escola é produzir contingentes de mão de obra mais ou menos qualificada para o mercado de trabalho. É a estrutura do mercado de trabalho que pressiona a escola com toda sua força, a ponto de imprimir sobre ela sua marca (BAUDELOT; ESTABLET apud GADOTTI, 1999, p. 198).
\end{abstract}

O ensino técnico foi uma forma de minimizar os problemas sociais e de fornecer uma mão de obra qualificada para as indústrias, que necessitavam de um contingente de pessoas preparadas para operacionalizar nas indústrias. No entanto, ao passo que nas escolas para elites o ensino era desenvolvido em sua integralidade, desenvolveu-se uma compartimentação entre 


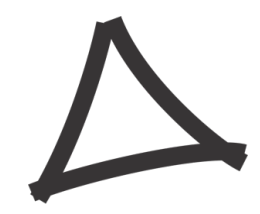

aqueles que serviriam para ser mão de obra barata e aqueles que seriam os patrões. Uma verdadeira distinção entre uma educação para os ricos e outra educação para os pobres.

Contudo, o ensino médio integrado ao ensino técnico não é garantia de uma integração e a dicotomia pode ainda estar presente, isso se a educação geral não for algo inerente à educação profissional. É necessária uma integração, no sentido pleno da palavra, de se tornar único, total, inteiro. Um ensino não fragmentado, mas que possibilite ao trabalhador uma dimensão intelectual, seu aprimoramento como pessoa humana, sua formação ética e a possibilidade do desenvolvimento de um pensamento crítico, a fim de superar a dicotomia entre trabalho manual e trabalho intelectual.

\section{CONSIDERAÇÕES FINAIS}

Ao voltar o olhar para o passado histórico brasileiro, observamos que as mudanças políticas e governamentais influenci(ar)am na estruturação da educação em nosso país. A cada alternância de poder ocorriam modificações, por Leis ou Decretos, que alteravam os currículos e as políticas educacionais. Evidenciou-se, então, que a educação era dualista, pois se diferenciava de acordo com a classe social, sendo que aos trabalhadores e aos seus filhos era destinada uma educação voltada ao mercado de trabalho. Por esse motivo, o ensino profissional, até os dias atuais é muitas vezes diferençado.

Dessa forma, podemos perceber que nossa educação, nada mais é que o reflexo de um país contraditório. A dualidade não está refletida apenas na educação, mas em várias outras áreas realçando as várias outras desigualdades existentes em nossa sociedade. Há de se dizer, que essas disparidades são estruturais sempre presentes na realidade brasileira. Como assegura Frigotto (2005, p. 11),

A imensa desigualdade educacional ganha compreensão neste contexto como expressão da forma de constituição de nossa formação histórica, de modernização conservação histórica, de modernização conservadora, de interdependência e dependência associada ao grande capital, de democracia restrita e de processos de revolução passiva e de transformismo (FRIGOTTO, 2005, p.11).

Portanto, a dualidade do ensino estudado nessa pesquisa deve ser entendida como um dualismo proveniente de uma sociedade fundamentada em uma estrutura desigual, no qual setores modernos se alimentam de setores atrasados, conforme afirma Frigotto (2005, p. 10), 


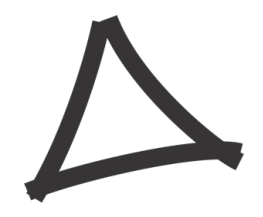

os setores denominados atrasado, improdutivo e informal se constituem em condição essencial para a modernização do núcleo integrado ao capitalismo orgânico mundial.

Desse modo, a formação profissional é sempre um fator a se considerar, pois quanto mais capacitado for o profissional melhor será sua atuação no mercado de trabalho, ou seja, em um mundo cada vez mais globalizado e com modernas tecnologias exige-se uma força de trabalho com melhor formação profissional. Portanto, antes de se fornecer uma formação profissional deve-se fundamentar a educação formal para todos. Educar com a finalidade primeira de desenvolver uma autonomia intelectual no educando e não para produzir uma mão de obra para o mercado de trabalho.

\section{REFERÊNCIAS}

ARAUJO, Ronaldo Marcos de Lima; RODRIGUES, Doriedson do Socorro. Referências sobre práticas formativas em educação profissional: $\mathrm{O}$ velho travestido de novo frente ao efetivamente novo. Boletim Técnico do SENAC. A Revista da Educação Profissional, Rio de Janeiro, v.36, n.2, maio/ago.2010.

BARONE, Rosa Elisa M. Formação Profissional: uma contribuição para o debate brasileiro contemporâneo a partir da experiência internacional. Boletim Técnico do Senac, Rio de Janeiro, 24(1): 13-25, jan./abr.1998.

BRASIL. Lei n. 9.384, de 20 de setembro de 1996. Estabelece as diretrizes e bases da educação nacional. Diário Oficial da União, Brasília, DF, 23 dez. 1996.

. Ministério da Educação. Portaria n. 4, de 06 de janeiro de 2009. Estabelecer a relação dos campi que passarão a compor cada um dos Institutos Federais de Educação, Ciência e Tecnologia, criados pela Lei $n^{0} 11.892$, de 29 de dezembro de 2008. Disponível em: $<$ http://www.ifrr.edu.br/acessoainformacao/institucional/portaria-n-04-de-12-de-janeiro-de2009 >. Acesso em: 29 mai. 2018.

CARVALHO, José Murilo de. Cidadania no Brasil: o longo caminho. 5. ed. Rio de Janeiro: Civilização Brasileira, 2004.

CIAVATTA, Maria. A formação integrada: a escola e o trabalho como lugares de memória e de identidade. In: ; FRIGOTTO. G.; RAMOS, Marise N. Ensino Médio Integrado: concepções e contradições. 3. ed. São Paulo: Cortez, 2005.

FREIRE, Paulo. Educação como prática da liberdade. 14. ed. Rio de Janeiro, Paz e Terra, 1983. 
FRIGOTTO, Gaudêncio. Fazendo pelas mãos a cabeça do trabalhador: o trabalho como elemento pedagógico na formação profissional. In: Cadernos de Pesquisa. Fundação Carlos Chagas, São Paulo, n. 47, p. 38-45, nov.1993.

; CIAVATTA. M; RAMOS, Marise N. Ensino Médio Integrado: concepções e contradições. 3. ed. São Paulo: Cortez, 2005.

GADOTTI, Moacir. História das ideias pedagógicas. 8. ed. São Paulo: Ática, 1999.

LIBÂNEO, Carlos José. O dualismo perverso da escola pública brasileira: escola do conhecimento para os ricos, escola do acolhimento social para os pobres. Educação e Pesquisa, São Paulo, v.38, n.1, p13-28, 2012.

MOURA, Dante Henrique. Educação básica e educação profissional e tecnológica: dualidade histórica e perspectiva de integração. Holos, Natal, v.2, p.1-27, 2007. 